\title{
Entre la paz y el caos. Acción subversiva y actividad pacificadora en las élites urbanas. Toledo, 1441-1495*
}

\author{
María José Lop Otín \\ Universidad de Castilla-La Mancha \\ Óscar López Gómez \\ Universidad de Castilla-La Mancha
}

RESUMEN: En la Castilla del siglo XV la paz, el orden público y la justicia dependian de los reyes, que, no obstante, estaban obligados a operar de forma consensuada, buscando los máximos apoyos posibles. En esa búsqueda las urbes se erigirían como los pilares sobre los que asentar el armazón de una Corona enérgica y cada vez más autoritaria, así que las élites locales acabaron por convertirse en un factor básico en la estabilidad o inestabilidad del reino. Una de las urbes castellanas en las que se dejó notar más la influencia de la élite fue Toledo, cuya actividad insurrecta en el siglo XV podría compararse con la de otros núcleos europeos famosos por su actitud facciosa, como Gante o Florencia. La élite social de Toledo procedería durante los reinados de Juan II, Enrique IV e Isabel la Católica de forma paradigmática en un doble sentido: en su capacidad para escandalizar a la población, provocando ruidos, alborotos y muertes; en lo relativo a las medidas pacificadoras que supo desarrollar con el fin de favorecer su propio dominio, el sometimiento de la urbe a los reyes y la prosperidad de la región.

Palabras Clave: Toledo; élite urbana; actividad subversiva; medidas pacificadoras; violencia; paz.

Between peace and chaos. Subversive action and pacification measures on the urban elites. Toledo, 1441-1495.

* Siglas de archivos y bibliotecas: ACJ: Archivo del Cabildo de Jurados; ACT: Archivo Capitular de Toledo; AMT: Archivo Municipal de Toledo; AS: Archivo Secreto; RAH: Real Academia de la Historia 


\begin{abstract}
In the fifteenth century peace, public order and justice depended in Castile on the kings, but these were forced to operate in a consensual manner, seeking the maximum possible support. In this search the cities will erect as the pillars on which to build the frame of a Crown energetic and authoritarian. Local elites, who had in their hands the governments of the cities, eventually became a factor basic in the stability or instability of the kingdom. One of the Castilian cities in which the influence of elites was more visible was Toledo, whose insurgent activity in the fifteenth century could be compared to other famous by factional attitude european cities, such as Ghent and Florence. The social elite of Toledo projections during the reigns of John II, Henry IV and Elisabeth I come from a model in two ways: in their ability to shock people, causing riots and deaths, but also relating to pacification measures in times of calm, in order to promote their own domain, submission of the city to the kings and prosperity of the region.
\end{abstract}

KEY WORDS: Toledo; urban elite; subversive action; pacification measures, violence, peace.

\title{
INTRODUCCIÓN ${ }^{1}$
}

Para las élites urbanas las estrategias de pacificación — se suponía por la pas e sosyego y por el bien común ${ }^{2}$ — y las actividades sediciosas — para escandalizar a la urbe - eran elementos de sus tácticas de dominio político, social y económico ${ }^{3}$. Tanto los procesos de sublevación como los de apaciguamiento eran trascendentales para sus fines en la medida en que permitían definir, de facto, el poderío de las facciones en que se estructuraba la oligarquía $^{4}$. De este modo, la diplomacia a nivel local y los convenios se desarrollaban en escenarios de una violencia por lo común no física, sino de carácter retórico-discursivo ${ }^{5}$, que deformaba todo proceso de negociación acerca del destino de la ciudad, manipulándolo en función de los intereses de parte de sus regidores. Los omes poderosos escandalizaban a sus convecinos para posteriormente pacificarlos en unas circunstancias muy concretas, generándose así una dinámica de tensión-distensión, en la que los alborotos eran seguidos

1 Este trabajo se ha realizado en el marco del Proyecto de Investigación «Impacto urbano, actividad productiva y sociabilidad en las villas y ciudades castellanas del eje económico Toledo-Burgos (1450-1520)», financiado por el Ministerio de Ciencia e Innovación entre 2011-2013 (HAR2010-15422) y dirigido desde la Universidad Complutense de Madrid por la profesora María Asenjo-González.

2 LÓPEZ GÓMEZ, 2006. JARA FUENTE, 2009-2010.

3 BENHAM, 2011: 3.

4 WILCOX, 2000: 89.

5 NIETO SORIA, 2004. 
por épocas de apaciguamiento, rupturas de treguas, ceses de hostilidades, más treguas, nuevos quebrantos del orden y, en definitiva, un tira y afloja continuo que podía alargarse durante años en beneficio de las élites implicadas ${ }^{6}$. Unas élites que hay que entender de manera global como un conjunto de linajes con un estatus superior, que dominaban la escena política, socioeconómica y cultural, y que tenían en sus manos las instituciones de gobierno y de la Iglesia. Y es que, no se olvide, el papel de los religiosos fue básico tanto a la hora de alborotar a la población como para pacificarla, gracias a su poder económico y a su capacidad de influencia en las masas sociales a través de entredichos, excomuniones, el control de la educación o, simplemente, los sermones que pronunciaban desde los púlpitos.

Los linajes oligárquicos lideraban motines y revueltas con el único fin de imponer su paz, o lo que es lo mismo, de conmover el régimen establecido ( $\sin$ cuestionarlo, pues se beneficiaban de él), haciéndolo más justo a sus intereses, mediante la manipulación de los consensos en torno al orden público, la sociedad, la política, el gobierno, la economía e incluso la cultura y la religión 7 . En estas circunstancias, tanto en el lenguaje subversivo como en el de carácter pacificador eran básicas nociones políticas en auge a partir del siglo XIV como bien común, paz, privilegios, ley, costumbre, derechos, libertad, unidad, justicia y concordia ${ }^{8}$. Se trataba de principios genéricos que, usados con demagogia, servían para legitimar argumentos que en el fondo llevaban a la imposición del poder. Lo que se quería con su uso era que la opinión pública quedase al servicio de las estrategias de las parçialidades. Para las élites la paçificación y la pas, como la violencia, eran un instrumento de dominio. Fue sobre todo a fines del siglo XV cuando en las élites urbanas de Castilla caló la idea de que para conseguir según qué metas, en ocasiones, eran preferibles las fórmulas paçificas de resolución de las disputas al terror ${ }^{9}$, si bien la violencia jamás fue excluida.

6 BENHAM, 2011: 9.

7 BLOCKMANS, 1996: 433-447.

8 DUMOLYN y HAEMERS, 2012: 72.

9 Arsenio Dacosta achaca este cambio de actitud, en lo que se refiere al País Vasco, a un cambio generacional y a la extensión de la cultura política propia del naciente estado moderno. Frente a la violencia, en Vizcaya comenzó a hablarse de igualar, combençión, pacto, transaçión: DACOSTA, 2010: 128. Lo más importante fue la cultura política emanada de la nueva concepción del estado. Los cambios generacionales en algunas ocasiones, lejos de favorecer la pacificación, hicieron que se enervase la violencia, como ocurrió en el caso de Toledo antes de las Comunidades de Castilla. LÓPEZ GÓMEZ, 2006b: 1.047-1.052. 


\section{LA ÇIBDAD ESTÁ ESCANDALIZADA... EL PROCESO DE SUBVERSIÓN DE LAS ÉLI- TES URBANAS}

Al igual que existía una dramatización del apaciguamiento, una dialéctica y una retórica de la paz, también había una lógica del alboroto que, no obstante, a menudo nos ha llegado entre la niebla del tiempo, como una sombra de lo que fue, interpretada por los cronistas de los reyes. En consecuencia, la mejor forma de conocer cuál era el procedimiento más común para escandalizar a una urbe es acudiendo a lo que sucedía en las calles, en las que los discursos pro-alzamientos, a favor de la insurrección, solían vincularse (los desplegara quien lo hiciese) a la lucha por la libertad y contra los opresores ${ }^{10}$, usando conceptos estereotipados de carácter político con una creciente carga subversiva como comunidad y justiçia. Si bien en el caso de la Corona castellana aún no se ha abordado un estudio sobre los diferentes discursos sediciosos de la Baja Edad Media ${ }^{11}$, está claro que las soflamas de las élites a la hora de alzar a la población se sostenían sobre el lenguaje que el pueblo deseaba oír (para ganárselo) aunque imbuido de la moral de guerra de la caballería, cuyos valores supremos eran el triunfo sobre los enemigos, el desprecio a la muerte, el coraje, el honor y la valentía ${ }^{12}$. El común contaba con su propio lenguaje político ${ }^{13}$, pero en los escándalos e alborotos de ciudades como Toledo el discurso que se oía con contundencia era el de la élite, la cual, paradójicamente, recelaba de las intenciones del común ${ }^{14}$, aunque soliera manipularlo en su beneficio mediante la mentira ${ }^{15}$, que en el fondo era una herramienta para destruir la paz y restaurarla. En algunos casos, las élites hacían uso de la mentira - los rumores - en pro del vulgo; y otras veces a su favor. Según su parecer, algunas creencias eran necesarias, aunque fuesen falsas. Lo que les confería legitimidad era la teórica búsqueda del bien común.

En este sentido, el análisis de las asonadas que solían perturbar el orden público evidencia también un protagonismo notorio de determinados líderes urbanos de la nobleza ${ }^{16}$ — no de extracción popular-, o al menos de familias

10 Veasé: COHN, 2008. Cuando Toledo se alzó contra la monarquía en 1520 una multitud se congregó ante las casas del corregidor gritando: ";Comunidad, Comunidad!, ;Libertad, libertad!»: VAQUERO SERRANO, 2000: 186-187.

11 Estos discursos cada vez son más importantes entre la historiografía medieval del Norte de Europa: DUMOLYN y HAEMERS, 2012: 72

12 GARCÍA VERA y CASTRILLO LLAMAS, 1993: 24.

13 MONSALVO ANTÓN, 2011.

14 En toda Europa las oligarquías consideraban las acciones de la clase baja una amenaza para la paz social y el orden público: COHN, 2008: 4.

15 BELTRAN, 2010: 291.

16 En Toledo, y en otras ciudades, los líderes del común en las revueltas fueron utilizados después, en el momento de la represión, para cargar sobre ellos las culpas de lo ocurrido, sal- 
de mercaderes o de la baja caballería. Para alborotar a una población era necesario que hubiese un líder carismático y vigoroso cuya determinación marcase el camino ${ }^{17}$, y que estuviera capacitado para exhibir su autoridad tanto en la rebelión y la violencia como en el apaciguamiento y la calma ${ }^{18}$. Ese líder, asesorado por sus consejeros, era el que debía establecer la estrategia a seguir por su grupo en virtud de las circunstancias, en una especie de escenificación cuyo fin era preparar a sus partidarios para la lucha. A él se vinculaban tanto los lugares de reunión de la parcialidad como los símbolos totémicos (especialmente las banderolas y estandartes) y las actitudes de los individuos más poderosos de la facción, de los que se esperaba que hicieran determinadas cosas en el momento de alzarse y hacer la paz ${ }^{19}$. Sus acciones debían ser reconocibles por los intervinientes en los tumultos - la clientela sociopolítica-, de modo que el líder y sus colaboradores no podían ser espontáneos en sus rituales, sino que debían seguir una serie de escenas programadas, con un léxico de la insubordinación destinado a facilitar el conflicto o un léxico de la paz cuyo fin sería imponer la mesura.

\section{La lucha callejera y su expresión ritual}

En lo que se refiere a la violencia de las élites, la organización y las estrategias de sus facciones eran similares en todas las urbes. Las clientelas seguían la táctica del líder del grupo, cuya postura era expuesta en principio en las instituciones públicas - en las que operaban los dirigentes de su parcialidad - hasta que, evidenciándose la inutilidad de su defensa, se decidía pasar a otro plano de acción, extrainstitucional ${ }^{20}$. El jefe de un grupo asumía una posición de consenso con sus colaboradores y se informaba a las clientelas para que, conocida su misión, actuasen en sus campos: Regimiento, Cabildo de jurados, audiencias de la justicia, parroquias, Cabildo catedralicio, fieles ejecutorías, veedurías, señoríos, ayuntamientos rurales. Si la postura no se lograba imponer, se exigía más presión en las instituciones, al tiempo que empezaba a actuarse fuera de ellas. Tenía inicio de este modo lo que algún

vando de esta forma el honor de los grandes líderes de la oligarquía. El ejemplo más paradigmático fue el del odrero anónimo que contribuyó a alzar a la urbe contra Juan II en 1449: LÓPEZ GÓMEZ, 2014.

17 FLETCHER, 2002: 129-130.

18 MARTINES, 2005: 39.

19 BENHAM, 2011. OFFENSTADT, 2000.

20 La política salía de las instituciones públicas y la violencia se politizaba, lo que podía acarrear consecuencias en verdad terribles. Es por ello que a la hora de pacificar a la población los Reyes Católicos tuvieron claro que tenían que volver a institucionalizar la política, despolitizando, a su vez, la violencia: LÓPEZ GÓMEZ, 2004. 
autor ha denominado una agresión ritualizada: una especie de lucha ficticia, teatralizada, retórica, discursiva y sin derramamientos de sangre, con ciertas reglas y compatible con la actuación dentro de la legalidad. Se trataba de un modo pautado de resolver el conflicto, cuyo fin era dramatizar la situación mediante la siembra del desconcierto, para que así, con el temor, las dudas y la desconfianza ante lo que podía avecinarse, se concluyeran las disputas, estableciéndose una paz beneficiosa para la facción rebelde ${ }^{21}$. Se trataba de alardes de poder en que no era tan trascendental lo que se exhibía a los enemigos - milicias armadas, movilizaciones vasalláticas, pendones, caballos, ballestas, artillería - como lo que a priori se ocultaba; existiera o no. El amedrentamiento era parte de un discurso en el que lo trascendente era la exhibición del poder y crear rumores útiles para determinados fines ${ }^{22}$.

Con frecuencia, los conflictos de las élites quedaban en esto; en una exhibición coercitiva y sistemática cuyo fin era desestabilizar el sistema. Se reunían arsenales con armas de todo tipo en los palacios de los jefes de la facción, se ocupaban edificios estratégicos ante una plausible lucha armada puertas y portillos de las murallas, parroquias, torre de la catedral-, se enviaban mensajeros a los señoríos para requerir a los vasallos que estuviesen listos para el combate, se ponían bajo control las barcazas que servían para cruzar el río - para impedir sorpresas inesperadas - , se presionaba al Regimiento para que no coartase la osadía de la facción rebelde ${ }^{23}$, se daban pregones subversivos por las calles o en los púlpitos, comenzaban a actuar espías por las zonas concurridas con la misión de conocer las repercusiones de lo que estaba pasando, y, lo más importante, se empezaba a reclutar a individuos para asistir a la facción insurrecta. Unos individuos que, organizados en grupos, deberían trabajar día y noche por las áreas más céntricas con el fin de amedrentar a la población con su actitud amenazadora - exhibían cuchillos, pavesas, lorigas, espadas, lanzas, ballestas - la impunidad de que gozaban -ni siquiera la justicia se atrevía a pararlos -24 y los disturbios de los que eran protagonistas: agresiones a prostitutas, insultos a alcaldes, robos de presos a los alguaciles, asesinatos, allanamientos de moradas, tomas de fortificaciones, entre otros. En estas circunstancias, lo habitual era que las autoridades buscaran el auxilio del sector de la oligarquía contrario al motín, al tiempo que se daban pregones por la paz pública, se echaba de la urbe a vagamundos,

21 MACKAY, 1991a y 1991b.

22 MACKAY, 1988: 158-163.

23 En ocasiones algunos miembros de la facción salían del edificio del ayuntamiento, quedándose a sus puertas, para que todo el mundo viese que algo no marchaba: Traslado de los autos que pasaron en el Ayuntamiento sobre que baya jurado por procurador de Cortes. Año de 1498, AMT, Archivo del Cabildo de Jurados, Traslados, caja 19, fol. 3 v.

${ }^{24}$ LACEY, 2009: 80 
e rufianes e gentes sin dueño nin señor conosçido, la circulación con armas y los juegos de apuestas eran prohibidos, se establecían toques de queda a última hora de la tarde, se movilizaba a las parroquias para que organizasen rondas $e$ velas, se ponía una vigilancia especial en los espacios peligrosos (tabernas, mancebías y mesones) y, por último, se nombraban árbitros que mediasen en la situación. Mientras, las facciones continuaban con su cometido.

Entre la documentación medieval toledana se han conservado textos de gran valía, que evidencian qué factores rituales y protocolarios entraban en juego una vez que la actitud sediciosa de una parçialidad era irreversible. El proceso de rebelión se desarrollaba en los lugares totémicos del grupo —el palacio del líder, su parroquia principal- y en las calles, y constaba de un cúmulo de acciones instituidas por la costumbre: juntas secretas, envíos de cartas amenazadoras, ocultación del líder, pregones sediciosos, crímenes selectivos, traslados de los bienes muebles a recintos eclesiásticos para que se acogiesen a sagrado, desfiles de hombres de armas, espionaje al rival. Existían una serie de elementos estereotipados que la población en su conjunto conocía, y ante los que reaccionaba de forma inminente, fuera quedándose en casa, poniendo bajo recaudo las pertenencias, escribiendo apresuradamente un testamento o sumándose a la lucha.

Era en los palacios de la oligarquía - con enormes salones, patios, un sinnúmero de cubículos, cuadras, mazmorras 25 - donde se articulaban las estrategias de acción política, las tácticas de rebelión del grupo y, una vez con la lucha en marcha, las medidas pacificadoras. El lugar más relevante era el salón del palacio del líder de la parçialidad ${ }^{26}$, sitio predilecto donde infatigablemente se reunían los cabecillas del bando, se realizaban alianzas, confederaciones y juramentos, se definía la táctica a seguir, se daban órdenes, se recibían embajadas, se aceptaba a nuevos integrantes en la clientela y se ocultaba a los esbirros que huían tras protagonizar algún alboroto ${ }^{27}$. Acudir al palacio del líder para reunirse con sus cabecillas era un hecho estereotipado en la lucha de facciones ${ }^{28}$. Para la clientela, sobre todo para sus miembros más bajos en el escalafón social, acudir allí era como acogerse a sagrado ${ }^{29}$. La

25 PASSINI, 2004: 28-106.

26 ROLLASON, 2009: 26-34.

27 El 5 de agosto de 1506 fue asesinado a golpes el jurado Diego Terrín a manos de unos hombres de los marqueses de Villena. El grupo de criminales salió a cometer su crimen del palacio del marqués y luego, una vez cometido, se refugio allí, para escándalo de toda la ciudadanía. Los asesinos quedaron impunes: LÓPEZ GÓMEZ, 2012a.

28 Están documentadas decenas de reuniones en las viviendas de los líderes de los Ayala y los Silva. Siempre que en ellas se presentaba una autoridad pública (algún alcalde, un grupo de jurados) encontraban al líder con alguno de sus colaboradores, y rápidamente acudían otros a la vivienda. LÓPEZ GÓMEZ, 2006b: 1.282-1.304.

29 LÓPEZ GÓMEZ, 2008b: 221-222. 
casa del líder era un espacio de impunidad una vez ejecutadas las órdenes salidas precisamente de ella: desde la divulgación de pregones y panfletos subversivos, o el toque de las campanas llamando a la revuelta, hasta la agresión a un mozo de la parçialidad enemiga. Ese palacio era el escenario por excelencia de los ritos de la facción: desde él se proyectaba la retórica agitadora, no solamente con hechos sino también con escritos y con soflamas públicas, cuyo fin era embaucar tanto a los miembros de las clientelas como a todo el común. Los pregones se convirtieron, no en vano, en una herramienta básica a la hora de promover el alboroto.

A fines de la Edad Media los pregones eran instrumentos de divulgación política. En ellos los líderes de la élite difundían su ideario con un lenguaje comprensible para el pueblo y sin sutilezas, que al simplificarse ganaba en radicalidad. Los pregones se usaron como una herramienta de lucha cardinal tanto por la élite como por los pecheros. Y lo mismo sucedió con los toques de las campanas ${ }^{30}$, cuyo tañer era sinónimo de escándalos (entre otras cosas). Los pregones y el repicar de las campanas eran parte de la gramática de la insurrección de la sociedad medieval, si bien en lo relativo a los procesos de rebeldía de las élites eran elementos de un acto ritual mayor, de una escenografía más o menos pautada, donde la acción de la muchedumbre era importante.

En efecto, en la gramática de la élite los pregones y el tañer de las campanas a menudo tenían lugar en el momento en que la facción estaba reunida. Eran lo que se denominaba en la época el ruido, cuya finalidad era advertir a la ciudadanía de lo que pensaban hacer los amotinados en defensa de sus intereses — por más que apelasen al bien común-. No era infrecuente que el ruido se produjera como parte de un ceremonial desplegado ante una muchedumbre de personas armadas (a imitación de las procesiones religiosas), y como culmen de una catarata de tensión iniciada por un insulto, por un acto cuya gravedad se consideraba lesiva para la honra de la facción.

Ocurrido el insulto, los miembros de las clientelas acudían al palacio del líder, que actuaba como cuartel general, y allí se desarrollaba una ceremonia del alzamiento. El 18 de abril de 1467 se produjo una de esas ceremonias en el palacio del conde de Cifuentes, líder de los Silva. Poco antes unos hombres habían agredido a Fernando el thenor y a su hermano, miembros de la parçialidad de los Ayala, quienes, como contrapartida, se habían juntado en casa de su líder, habían constituido un grupo armado y habían hecho repicar las campanas de la iglesia de Santo Tomé llamando a los vecinos a un alzamiento en contra de los agresores: los Silva, según los Ayala ${ }^{31}$. Eso fue interpretado como un desafío, así que el conde de Cifuentes convocó una asamblea en su palacio, donde ante escribano público tuvo lugar una ceremonia de carácter

30 MARTÍNEZ GIL, 2002: 327-329.

31 LÓPEZ GÓMEZ, 2008a: 59-61. 
subversivo. Primero habló el conde para aclarar lo ocurrido, sin reconocer que quienes habían atacado al thenor eran de los suyos y concluyendo, así, que sus rivales querían levantar al pueblo contra el dicho conde e sus parientes, $e$ criados e alyados. Luego tomaron la palabra otros líderes de la facción, cuyos discursos se centraron en censurar al conde de Fuensalida - líder de los Ayala-, exigiendo que en adelante nadie le obedeciese en su condición de alcalde mayor. Ni a él ni a sus alcaldes. Se rompía de este modo con la apariencia de legalidad que la facción había mantenido hasta el momento en sus actuaciones, lo que se pidió al escribano que fuera notificado a sus enemigos. Posteriormente, para sellar lo establecido, se requirió a la clientela un juramento de lealtad hacia la causa. Y, por último, todos se unieron en un grito común (era la voz de la facción) clamando que ${ }^{32}$ :

...[se] allegavan e allegaron a lo sobredicho, e ponían e pusieron la dicha sospecha en el dicho Señor Pero Lópes e su ofiçio, e alcalldes, segúnd que'l dicho conde la avýa puesto e jurado....

Los gritos estereotipados eran esenciales en un alzamiento. La rebelión - como la paz- hay que gritarla. La rebeldía se reclama, se grita, es manifestada con la voz de los insurrectos. Es una palabra pública que sirve de catarsis. En épocas de tensión el grito de la lucha permite pasar del miedo al coraje, del temor a la valentía (al igual que en los tiempos de la paz señala el fin del mal y el inicio del bien). Emociones y dramatización van de la mano. El grito es testimonio del vigor resucitado de la parçialidad, por lo que no se produce de forma espontánea ${ }^{33}$. Se trata de un acto establecido que sanciona el buen desarrollo de las diversas partes de la subversión y su gramática ceremonial ${ }^{34}$, en la que también eran importantes la terminología de los discursos, los juramentos y la noche, período por excelencia para el escándalo. Toledo era célebre por sus noches ${ }^{35}$, en las que las parcialidades enviaban a sus grupos armados a las calles para perturbar a la población.

Como culmen del protocolo subversivo, en ocasiones acababa celebrándose un desfile de la insubordinación en la que el líder del grupo, escoltado por sus cabecillas, se ponía al frente de su clientela armada, y con escribanos, pregoneros y tambores se echaba a las calles, recorriendo las zonas más concurridas de la urbe en medio del estruendo provocado por una turbamulta que sólo callaba cuando debía darse un pregón, en una plaza o allá donde hubiera

32 Este libro es de traslados de cartas para los reyes y para otras personas, y para las simples de poca ynportançia. XV. XVI, AMT, Sección B, $\mathrm{n}^{\circ} .120 »$, fol. $205 \mathrm{r}-\mathrm{v}$.

33 También se gritaba en las juntas parroquiales una vez elegido un jurado, para ratificar la elección. Era la voz de la parroquia: LÓPEZ GÓMEZ, 2012b: 738.

34 OFFENSTADT, 2007: 291-297.

35 IZQUIERDO BENITO, 1994. 
mucha gente ${ }^{36}$. A veces, los líderes de la parcialidad iban con varas de justiçia simbolizando que ellos tutelaban a la población, y no las autoridades establecidas ${ }^{37}$. Unas autoridades que en alguna ocasión también hicieron uso de actos multitudinarios en las calles ${ }^{38}$, rodeadas de centenares de vecinos, para imponer la paz, aunque costase muchas vidas. Ante respuestas tan contundentes era factible que terminara por provocarse una auténtica guerra, de modo que no era difícil ver a los jurados, una de cuyas misiones era garantizar el orden, haciendo lo posible por que no se contestase a una manifestación subversiva sacando más hombres con armas a la calle, cuyas consecuencias podían ser terribles.

\section{La violencia colectiva y los eclesiásticos}

El papel de los eclesiásticos en la acción colectiva fue enormemente relevante, si bien muy a menudo se confunden las actitudes de determinados religiosos con la labor de la propia Iglesia como institución. La Iglesia - ni a nivel institucional ni como conjunto de eclesiásticos- favoreció las rebeliones urbanas. Al contrario que los linajes de la élite, era partidaria de mantener un status quo donde reinara la unidad e la tranquilidad. Y aun así, siempre que hubo graves disturbios la Iglesia fue protagonista (en 1449, 1467, 1520) debido a la actitud de determinados sujetos que pertenecían a las clientelas de los omes poderosos: desde algunos canónigos y frailes hasta el propio deán catedralicio, que alguna ocasión llegó a ser un pariente de los Ayala.

A pesar de que los lugares y edificios sagrados estaban obligados a garantizar la paz dentro y fuera de sus muros, muchos de ellos tuvieron que gestionar un buen número de hechos violentos que se desarrollaban en su interior, afectando a clérigos y fieles. Las violaciones de la paz de los templos obligaron a sus responsables a desempeñar una labor preventivo-represiva del delito en colaboración con las fuerzas del orden ${ }^{39}$. Por otro lado, los constantes alborotos que se produjeron en las calles tendrían también un notable efecto sobre las numerosas instancias eclesiásticas asentadas en la ciudad. Sin despreciar el papel de las veintisiete parroquias - latinas y mozárabes - con que contaba Toledo y de los clérigos a su cargo, fueron la catedral y su cabildo los sectores más afectados por el clima de insurrección. En el periodo que nos

36 El jueves 26 de noviembre de 1506 el conde de Fuensalida y su clientela desarrollaron una manifestación de este tipo: LÓPEZ GÓMEZ, 2006b: 1.293.

37 LÓPEZ GÓMEZ, 2012a:

38 En 1478, por ejemplo, en tiempos del corregidor Gómez Manrique. Según las crónicas llegó a reunir más de 2.000 vecinos: LÓPEZ GÓMEZ, 2008a: 224-225.

39 LÓPEZ GÓMEZ, 2008b: 191. 
ocupa ambos estaban en plena madurez y constituían el auténtico eje de la vida religiosa de la urbe ${ }^{40}$. Sus catorce dignidades, cuarenta canónigos y cincuenta racioneros, por citar sólo al personal más relevante, estaban emparentados con los bandos y familias que controlaban la ciudad, lo que les impidió aislarse del clima de tensión que reinaba en la misma. La documentación catedralicia, especialmente las Actas Capitulares, registran desde 1466 un buen número de sesiones dedicadas de forma específica a dirimir las querellas y conflictos que afectaron a la corporación, alterando la rutinaria cadencia en que, en teoría, transcurría el día a día en el templo. Tal documentación, con sus silencios y mensajes entrelíneas, identifica a la Iglesia en su conjunto como una víctima de la violencia colectiva.

El primer afectado fue el propio edificio catedralicio, al que es frecuente ver sirviendo de escenario a muchos de los acontecimientos vividos por la ciudad y cumpliendo un significativo papel en los altercados. Así, el tañido de su campana mayor servía para convocar al pueblo; su torre fue refugio de muchos rebeldes y fue atacada desde el exterior en más de una ocasión; las naves y capillas del templo presenciaron enfrentamientos y luchas armadas. Son actos impropios de unos espacios en los que se debía guardar una paz física y espiritual por albergar la representación simbólica de Cristo, pero en los que en la práctica se cometía más de un abuso. Baste como ejemplo el encastillamiento que sufrió la catedral en 1472, durante el cual la principal preocupación del cabildo era la dificultad para ir a dar las horas y oficios divinos segun debyan y eran obligados... A ello se sumaba el temor de que los objetos que componían el tesoro catedralicio y se guardaban en el sagrario se rompieran o fueran robados con tanta gente merodeando a su alrededor ${ }^{41}$.

Más allá de los inconvenientes que sufrió la catedral —o algunas parroquias o conventos, que serían ocupados militarmente-, los verdaderamente afectados por la violencia colectiva auspiciada por las élites fueron los propios capitulares, que en el ardor de los conflictos eran objeto de injurias e insultos, así como de robos y extorsiones en sus casas; actos todos ellos que vulneraban el privilegio de libertad eclesiástica de que gozaban, y que debía protegerles de cualquier intervención de los poderes laicos o de particulares en sus bienes y personas ${ }^{42}$. Los agravios y acusaciones que en el contexto de las contiendas urbanas recibieron estos altos clérigos por parte de autoridades municipales, vecinos, e incluso de otros capitulares que apoyaban al bando contrario fueron constantes. Frecuentemente, eran extorsionados durante el

40 LOP OTÍN, 2003 y 2005.

41 ACT, Actas Cap. I, ff. 46v-47v. Los encastillados fueron los canónigos Juan de Morales, deán de Sevilla, y Francisco de Palencia, prior de Aroche, que apoyan a Enrique IV frente al arzobispo Carrillo y otros sectores de la ciudad que se levantan contra él y su privado.

42 LOP OTÍN, 1999. 
trayecto hasta la catedral; los alborotadores los perseguían desde sus casas, entraban en el templo y dificultaban las celebraciones de los oficios. Eso llevó al cabildo a solicitar a las autoridades municipales que pusieran remedio a los ynsultos porque los beneficiados puedan venir seguros a la yglesia, y les hicieron responsables de los daños y menoscabos que estas situaciones les ocasionaran ${ }^{43}$.

El temor de los religiosos explicaría, al igual que su pertenencia a las clientelas de la élite, por qué entre los bienes de algunos de ellos había, junto a libros u objetos litúrgicos propios de su oficio clerical, armas (preferentemente ballestas de acero y espadas), y por qué entre sus servidores predominaban los pajes y escuderos. Especialmente inadmisible era sufrir actos violentos por parte de los propios compañeros de cabildo o del clero inferior a causa de rencillas, envidias y resentimientos. En unos momentos en que el asunto converso estaba muy presente, entre las acusaciones y los ynsultos más habituales estaban los de converso, confeso, judio o tornadizo, palabras que iban en contra de la convivencia y la caridad fraterna que debía reinar entre todos. Por ello, el cabildo solía penar a los que profirieran esas verba contumeliosa vel injuriosa - a menudo durante los oficios litúrgicos- con la suspensión de asistencia al coro y la correspondiente privación de las distribuciones cotidianas ${ }^{44}$.

Ahora bien, si la Iglesia en su conjunto sufrió las consecuencias de las actividades de sublevación de las élites, algunos de sus miembros, imbricados con aquellas, favorecieron dichas actividades de forma pública y privada. Tal vez el episodio más radical se vivió en el inicio del alzamiento de 1449. El escándalo se produjo cuando a un artesano (un odrero pobre) se le repartieron ciertas doblas: una cantidad muy alta para su poderío económico. Mientras le llevaban preso por impago, a voces empezó a llamar a la rebelión para impedir injusticias como la que estaba sufriendo. Y el común se alzó. Repicaron las campanas de la catedral y una turbamulta de vecinos se congregó en la plaza frente al templo, donde, rodeados de hombres armados, tomaron la palabra los canónigos Pero López de Gálvez y Juan Alonso para pedir a la población, entre gritos y arengas, que marchase a la casa del recaudador Alonso Cota, la saquease y quemase, como así ocurrión 45 .

El clero catedralicio no era sólo un agente pasivo en las acciones violentas que afectaron a la ciudad y sus habitantes. Los eclesiásticos vinculados a las clientelas de la élite participaban en todos los actos de la insurrección: desde los protocolarios y rituales - reuniones en los palacios de los jefes de la parçialidad, entrevistas secretas, gritos colectivos, juramentos- hasta los más

43 ACT, Actas Cap. I, f. 21v.

44 Numerosos testimonios en las Actas de los años 1467-1472.

45 NETANYAHU, 1999: 279. 
crudos e impetuosos - toques de campanas, difusión de pregones, espionaje, acaparamientos de arsenales de armas, agresiones físicas ${ }^{46}$ - En el verano de 1467 , por ejemplo, la violencia se suscitó en la catedral, y de hecho conocemos lo ocurrido, amén de por otras fuentes, gracias al relato de primera mano que hizo un mes después el canónigo Pedro Gómez de Mesa ${ }^{47}$. Aunque desde la primavera de ese año se observaba una creciente escalada de violencia, el origen concreto del conflicto está en el domingo 19 de julio, cuando, después de celebrada la misa mayor en el altar del templo primado, se entabló una discusión al hacerse público desde el púlpito el entredicho impuesto por el cabildo contra la ciudad de Toledo a causa de su intromisión en el cobro de unas rentas en Maqueda, lugar de su señorío. Ello generó una grande alteración entre el canónigo Fernando Pérez de Ayala y el alcalde mayor Álvar Gómez, que se cruzaron grandes debates e palabras muy deshonestas. Pero el conflicto enseguida traspasó lo que podría ser un mero enfrentamiento Ayuntamiento/Cabildo, pues en una y otra instancia se organizaron dos grupos: los partidarios de una negociación y del pago a la corporación catedralicia de una fianza de diez mil doblas, todo esto para restaurar la enjuria; y los que no admitían el acuerdo y apostaban por el enfrentamiento. Los primeros recibían el respaldo de los cristianos viejos, con los Ayala al frente; y los segundos, comandados por los Silva, eran conversos que se oponían vivamente a la corporación catedralicia. La ciudad se escandalizó durante varios días y sufrió destrozos, incendios y saqueos, amén de una importante pérdida de vidas humanas.

No es este el momento de volver a relatar unos hechos bien conocidos ${ }^{48}$, pero sí de aclarar algunos puntos. En primer lugar, que, igual que el resto de la población toledana, el clero catedralicio se dividió, teóricamente a causa del conflicto ocurrido en el templo y por sus implicaciones, pero en el fondo por los intereses ocultos que movían a los distintos sectores de la élite. Así, frente a la postura anticonversa que tomaron los canónigos Fernando Pérez de Ayala - hermano del alcalde mayor Pedro López de Ayala - y Juan Pérez de Triviño, está la del canónigo y prior de Aracena, Fernando Gómez de Villarreal — hermano del otro alcalde mayor, Alvar Gómez de Ciudad Real- y uno de los más destacados dirigentes del bando converso. Su oposición a los Ayala, le convirtió en objetivo prioritario de la furia popular anticonversa, explotada por la facción del conde de Fuensalida, de forma que no le quedó

46 LÓPEZ GÓMEZ, 2006c: 488.

${ }^{47}$ Los hechos se detallan en una carta dirigida por dicho canónigo a un gran señor toledano, decantado, como él, a favor de los cristianos viejos. Su contenido en MARTíN GAMERO, 1979: 1.040-1.045, de donde están extraídas las frases textuales incorporadas en el texto.

48 Una reciente reflexión sobre ellos en IZQUIERDO BENITO, 2011. 
más remedio que refugiarse en la capilla de San Blas, ubicada en el claustro del templo catedralicio, en tanto se calmaban los ánimos ${ }^{49}$.

En este sentido, un segundo aspecto en torno a lo ocurrido en 1467 sería el de la indefensión tanto del propio edificio catedralicio como de parte del clero, que vieron como irrumpía en la catedral un grupo de hombres muy armados con poco temor de Dios [...] las espadas sacadas e con corazas, que gritaban en contra de la Iglesia y sus canónigos, diciendo ¡mueran, mueran, que no es esta eglesia, sino es congregación de malos e viles! Pronto de las palabras pasaron a los hechos, llegando a apalear y a acabar con la vida de algunos miembros del cabildo. Como reacción y a fin de garantizar su defensa, en los días siguientes éste no dudó en solicitar el socorro de algunas parroquias de la ciudad y de sus vasallos de la cercana población de Ajofrín, que una vez en la urbe, al grito de iSancta María, Sancta María! (de nuevo un grito estereotipado), consiguieron impedir que se prendiese fuego a la catedral por los partidarios de los conversos, que de este modo pretendían obligar a los canónigos allí sitiados a que salieran. El resultado fueron más de cien muertos y - aunque el templo no ardió - decenas de casas y tiendas fueron arrasadas. El papel, no sólo de la catedral, sino del resto de edificios religiosos fue activo a lo largo de esos tensos días. Monasterios y parroquias guarecieron muchos conversos con sus faciendas, lo cual no impidió que las torres de algunas de esas iglesias sirvieran para colgar a los cabecillas de la contienda, alegando que esa era la justicia que manda hacer la comunidad de Toledo a estos traydores, capitanes de los conversos herejes...

\section{POR LA PAS E SOSYEGO... MEDIDAS DE PACIFICACIÓN, ESTRATEGIAS DE IMPO- SICIÓN}

Una vez con la urbe escandalizada, las facciones procedían a negociar algún tipo de pacto de fin de la disputa que pudiera ser esgrimido estratégicamente, con el deseo de que se impusiera su voluntad. Se trataba de una táctica de lucha ${ }^{50}$. Lo relevante no era alborotar a la çibdad sino sosegarla en unas condiciones precisas, beneficiosas para la parçialidad que la hubiera escandalizado. En consecuencia, los acuerdos de paz y las treguas solían usarse para conseguir períodos de descanso en campañas de insurrección que podían alargarse en el tiempo, y, sobre todo, para maniobrar con el anhelo de concordia de los rivales, imponiéndoles una pacificación a un precio muy alto ${ }^{51}$.

\footnotetext{
49 ACT, Actas Cap. I, f. 7r.

50 LAVELLE, 2000: 45-46.

51 FORONDA y CARRASCO MANCHADO, 2008; NOGALES RINCÓN, 2012.
} 
Los recursos de la élite a la hora de hacer la paz eran muy complejos, pues debían permitirle bascular entre el ejercicio de su poder y la aceptación de ciertas imposiciones del discrepante, apelando, eso sí, a una terminología política legitimadora - amor, amicitia, concordia, tranquilidad, pacto, acuerdo, bien común, guarda, defensa - . A la hora de hacer la paz, existía una gramática de gestos y un glosario terminológico que facilitaban la resolución de los conflictos $^{52}$. Es lo que Nicolas Offenstadt denomina el léxico de la paz, desplegado - como el léxico de la insurrección - con una escenografía muy concreta $^{53}$, cuyo lenguaje retórico lo articulaban tres principios: un rechazo de la violencia (sobre todo de la que vertía sangre cristiana); una constatación de los sentimientos pacíficos anclados en el corazón de los líderes de las facciones, a pesar de sus intrigas; y un deseo de imponer la paz por todos los medios, independientemente de los sacrificios y cesiones.

A la hora de emprender la pacificación era determinante que hubiera un grupo neutral en la élite que actuase de intermediario (transformando los mensajes y acercando a los líderes en liza) y amigos y parientes mutuos que favorecieran el compromiso y la negociación ${ }^{54}$. Pero también era esencial la actitud de los líderes de las facciones. En el siglo XV la violencia y la paz seguían siendo asuntos muy personales en Castilla. Aunque se empleaban delegados y lugartenientes, las transacciones cara a cara se solían apreciar por encima de todo, pues el liderazgo no sólo se demostraba en la batalla sino también en la negociación, defendiendo los intereses del grupo con dignidad, honra e inteligencia. Pacificar era básico en las relaciones de poder, aunque aún debe investigarse mucho sobre las prácticas y los ritos de la paz; especialmente por parte de los historiadores de las ciudades ${ }^{55}$, en las que con un supuesto fin pacificador las élites se aprovechaban de lo oral y lo escrito, del poder y la propaganda, de los juegos y espectáculos, de las ceremonias y de la (des)información. En la mayoría de las ocasiones todo era puro artificio. Las parçialidades tenían su propia concepción de la paz, y lo que pretendían era utilizar el término para imponer sus pareceres. Es por tal motivo que en muchos casos la paz lograda era lo que los teólogos medievales definían — según Jehangir Yezdi Malegam - como el Sueño de Behemoth: una diabólica y falsa paz de laxitud y complacencia, producida por unas desapropiadas formas de sosiego y amistad ${ }^{56}$.

52 MUÑOZ GÓMEZ, 2009: 694. SANMARTÍN, 2010: 415-416.

53 OFFENSTADT, 2007: 13-17.

54 Por eso las paces se sellaban con matrimonios, con el fin de que en caso de nuevos conflictos los familiares comunes actuaran como pacificadores: BENHAM, 2011: 188.

55 WOLFTHAL, 2000: XI-XII. SANMARTÍN, 2008: 413. BENHAM, 2011: 1. OFFENSTADT, 2007: 25-26.

56 YEZDI MALEGAM, 2013: 153-189. 


\section{EI Sueño de Behemoth y la paz de la oligarquía}

En el ámbito urbano la paz llegaba en la mayoría de las ocasiones como consecuencia de la tensión política, la amenaza de que la violencia acabase por perjudicar a la élite en su conjunto y, en fin, las pautas infrajudiciales y de resolución de los conflictos de las oligarquías ${ }^{57}$. A las propias élites les interesaba que, una vez con los vecinos escandalizados, se implementasen procesos de pacificación que les permitieran devolver a la ciudadanía un nivel razonable de paz. Con ello pretendían construirse una buena imagen entre el pueblo; buscaban inculcar a la opinión pública la idea de que sus facciones eran pacíficas y perseguían el serviçio del dicho señor rey e el bien e pro común desta dicha çibdad ${ }^{58}$, si bien la confrontación de intereses a menudo obligaba a recurrir a la violencia ${ }^{59}$. En todo caso, el coste de la paz podía ser altísimo para algunos sectores de la élite.

En Toledo apenas se firmarían tratados de paz en el siglo XV. El más famoso se rubricó en la primavera de 1475 para concluir con dos décadas de conflictos entre facciones, y fue sellado a través de un matrimonio entre un Ayala y una Silva ${ }^{60}$, tras realizarse todos los actos establecidos en la gramática de la paz ${ }^{61}$ : un banquete conjunto, una ceremonia religiosa, intercambios de regalos y cesiones de territorios y castillos en garantía. Empero, en la ciudad del Tajo las paces como ésta no fueron comunes. Los costes se valoraban excesivos y comprometían a seguir una dinámica de quietud que no era la de las facciones, de modo que lo habitual era que se lograran treguas más o menos duraderas (de entre cuarenta y ocho horas y seis meses), que irían renovándose sólo de ser necesario, si antes de su liquidación no se había establecido una concordia.

En las treguas también se guardaba un protocolo ceremonial, aunque más simple y de menos ostentación que en las paces definitivas. Al igual que en las firmas de la paz, en las treguas los intervinientes nombraban a un equipo de gestión del protocolo del apaciguamiento, que entre otras tareas se encargaba de las ceremonias que debían realizarse, teniendo en cuenta cinco cuestiones: los lugares en que se reunirían los jefes de las parcialidades para discutir los acuerdos, los actos públicos y simbólicos, los delegados de cada facción en las negociaciones - y el poder del que debían gozar-, los juramentos que habían de hacerse y las garantías a otorgarse ${ }^{62}$. En lo relativo a lo

57 NIKICHINE, 2006: 3-10.

58 Tregua del 6 de octubre de 1458: AMT, AS, caj. 5, leg. 6, no 4.

59 JARA FUENTE, 2009-2010: 109.

${ }^{60}$ LÓPEZ GÓMEZ, 2006: 725-727

61 OFFENSTADT, 2007: 185-226. KERSHAW, 2011: 19.

62 BENHAM, 2011: 11-12. 
primero, en algunas treguas (al contrario que en los tratados de paz) no era obligatorio que los líderes de las facciones se juntaran en público en un lugar específico - la catedral, un monasterio, un convento-. Las juntas de negociación se celebraban en secreto, de modo que no han dejado rastro alguno. Y una vez lograda una concordia se escribía ante notario y se realizaba un acto ceremonial de rúbrica que, empero, no tenía por qué celebrarse en un espacio específico, todos juntos, sino que era el grupo de gestores del proceso el que acudía al espacio territorial de cada facción - por lo común el palacio del líder, o su parroquia - para hacer los oportunos ritos y formalidades de forma diferenciada. También sucedía así en otro tipo de acuerdos entre facciones: los que se refrendaban para establecer qué armas se podrían usar en una hipotética disputa ${ }^{63}$. Los elementos ceremoniales que compartían en la ciudad del Tajo las treguas, las paces y estos pactos eran en básicamente: la jura, el pleito homenaje y los pregones de la noticia.

Al igual que la propia pacificación, también se negociaban los componentes del equipo que se encargaría de la ceremonia que había de hacerse para instituir el acuerdo de forma oficial. El equipo solía estar formado por personas con un estatus superior en las facciones - pero no por los líderes principales - , por ayudantes de protocolo (notarios y pregoneros) y por eclesiásticos, cuya labor era básica en el proceso de pacificación. En el equipo había dos personas con un cometido muy destacado. Una era la encargada de recibir el juramento de acatar lo convenido por los líderes de las facciones. Solía tratarse de un miembro consensuado de la jerarquía eclesiástica de la urbe. La otra persona era la que tenía el cometido de recibir de los líderes de cada parcialidad un pleito-homenaje, por lo que debía contar con poderes extraordinarios, de modo que habitualmente se trataba de un delegado de la Corona.

La retórica del discurso era similar en las paces, las treguas y los convenios sobre el sistema de lucha a seguir por las facciones. En todos los casos se esgrimían las palabras unánimes y conformes a la hora de referirse a las cláusulas del convenio y a su legitimación. Se trataba de una fórmula retórica impuesta por la costumbre que, en todo caso, había de ser aprobada por los líderes de las facciones, al igual que los espacios y los tiempos, es decir, a dónde debían acudir los gestores de la paz y con qué prelación ${ }^{64}$. Del mismo modo, en el protocolario ritual se habían de tener en cuenta las celebraciones religiosas y los domingos, tanto por razones propiamente ceremoniales como por motivos prácticos. Las juras y los pleitos homenajes no se tenían porqué realizar en un día sacro, pero sí la proclamación pública de lo establecido, para

63 Concordia sobre el sistema de lucha del 12 de diciembre de 1506: LÓPEZ GÓMEZ, 2012a.

64 Primero se iba a las casas de los líderes de las parcialidades y, de ser necesario, posteriormente a las casas del corregidor: LÓPEZ GÓMEZ, 2006b: 1.301. 
concederle una certificación religiosa ${ }^{65}$. Por otra parte, los domingos y las fiestas eclesiásticas entraban en el tiempo del ocio, así que era más fácil hallar a personas por la calle que escucharan los pregones sobre lo instituido, y que los difundieran.

Antes de la proclamación de los acuerdos, una vez en los palacios de los líderes de las parcialidades, en un monasterio o en el claustro de la catedral - lugares instaurados por la costumbre para refrendar pública y ceremonialmente los convenios-, se leía lo acordado y se hacía un juramento y un pleito homenaje. A la hora de jurar la persona encargada del acto debía sostener entre las manos un libro de los evangelios o una cruz que los líderes de las parcialidades irían tocando con la mano derecha, al tiempo que se les echaba la confusión del dicho juramento, a lo que deberían responder isí, juro! y ¡amén! ${ }^{66}$.

El pleito homenaje, por su lado, se recibía como cavalleros e omes fijosdalgo, una e dos e tres veces, hasta nueve, según fuero e costumbre d'España. El encargado de recibirlo tomaba las manos de la persona que lo hiciera entre las suyas (ante el escribano y los testigos presentes), y le leía la fórmula protocolaria del pleito homenaje. Si la jura sobre la cruz o los evangelios confería al acto una unción religiosa, el hecho de coger las manos tenía evocaciones políticas y militares relacionadas con su utilidad para hacer la guerra, proteger al pueblo y guardar el favor del rey. Al contrario que en otras ceremonias, el proceso ritual acababa ahí. Puesto que los jefes de las parcialidades podían reunirse en lugares diferentes, no hay referencias escritas al desarrollo de actos protocolarios para robustecer lo establecido tales como apretones de manos, abrazos o, algo muy común a la hora de hacer la paz, un beso entre los líderes de las facciones enfrentadas ${ }^{67}$.

Concluidas las ceremonias, la proclamación de lo acordado tenía lugar de manera preferente en domingo, a través de pregones. Existía un circuito oficial — las calles acostumbradas - , en el que la justicia ejecutaba las penas de sus reos, donde las parcialidades realizaban sus procesiones de subversión y donde, finalmente, tenían lugar los actos protocolarios de publicación de la paz y las treguas. En ellos intervenían los delegados de las facciones y muchos religiosos - quienes a la postre serían los encargados de difundir la noticia en el púlpito-, además de mucha gente aiuntada. Por lo común se daban tres pregones a altas voces en las tres plazas principales: delante de la

65 OFFENSTADT, 2007: 165-184.

${ }^{66}$ Los hombres que habían de encargarse del protocolo estaban en la obligación de hacer que todos los caballeros juraran la concordia, lo que difícilmente era viable en una jornada, de manera que su cometido se solía alargar durante días o meses. La paz del 6 de octubre de 1458, por ejemplo, estuvo jurándose hasta el 22 de febrero de 1459.

67 PETKOV, 2003. 
catedral (en la Puerta del Perdón), en las Cuatro Calles y en Zocodover ${ }^{68}$. Requería tal esfuerzo la publicación de la paz a gritos que a veces intervenía más de un pregonero.

\section{La paz urbana y el clero de la catedral}

Si para la oligarquía la consecución de la paz y la devolución de la calma a las ciudades y sus habitantes siempre estuvo en el punto de mira, para los eclesiásticos se trataba de algo más elevado: una suerte de mandato divino. Los clérigos asumían, al menos teóricamente, que la religión era generadora de la paz, y así se escenificaba en la misa, continua sucesión de himnos y de plegarias en alabanza de la paz entre Dios y los hombres, y de estos entre sí. Una paz que debía ser física y espiritual, y que aludía tanto a la necesidad de oponerse a la violencia como a la búsqueda de la armonía y el orden que debía reinar en la sociedad ${ }^{69}$. En esa búsqueda de la concordia entre los fieles y vecinos el cabildo de la catedral primada contribuyó con diversas medidas, en especial en los momentos posteriores a los grandes períodos de insurrección colectiva. Así se debe entender, por ejemplo, que el cabildo cediera el edificio catedralicio para escenificar en él los más variados acuerdos de paz: tanto entre los oligarcas como, sobre todo, entre la población, en su conjunto, y la monarquía. Independientemente de que otros espacios urbanos como puertas y plazas acogieran actos rituales llenos de simbolismo, los que se desarrollaban en la catedral no tenían parangón por la propia espectacularidad del edificio. Es lo que sucedió en enero de 1477, cuando los monarcas vinieron a la ciudad para apoyar a su corregidor Gómez Manrique. Tras llegar a la catedral y ser recibidos por el cabildo, se realizó una dramatización en un corredor, sobre la portada gótica, donde había un grupo de personas vestidas de ángeles y en medio una doncella ricamente vestida con una coraza de oro en la cabeza, a semejanza de la Virgen ${ }^{70}$. Y algo parecido sucedió en 1480, cuando la catedral sirvió de marco a un solemne acto de profundo significado político: la jura de don Juan, heredero de los monarcas, con ocasión de la celebración en Toledo de las decisivas Cortes que pondrían las bases de la nueva monarquía autoritaria y estable.

Todo ello es prueba evidente de que el recinto catedralicio se había convertido en un símbolo para la ciudad y sus habitantes y, de la misma manera que estaba afectada por el conflicto, se veía involucrada en la escenificación

68 La concordia lograda en octubre de 1458 tuvo que pregonarse, además, en la plaza de Santo Tomé, junto los palacios de los Ayala

69 MULLET, 1990: 56-57.

70 LÓPEZ GÓMEZ, 2008a:109. 
de la paz. Allí se celebraban todo tipo de actos ceremoniales y misas pro pa$c e, \mathrm{y}$ desde el templo partían procesiones cuya finalidad era precisamente esa, rogar por la paz. En ocasiones lo hacía de modo indirecto, clamando por la salud de los reyes, por la victoria frente al enemigo o para que se lograra un pacto de colaboración entre reinos ${ }^{71}$. En dichos rituales se utilizaban objetos litúrgicos no empleados de manera habitual en las misas, se pronunciaban homilías en las que el pueblo era concienciado sobre las implicaciones de lo que se pedía a Dios, los clérigos llevaban sus mejores ropajes y se entonaban cánticos de alabanza: Gloria in excelsis Deo, Hanc igitur, Libera nos, Te Deum laudamus.

El papel de los religiosos no implicados en los conflictos ni en las clientelas de las élites era esencial a la hora de establecer cualquier tipo de pacificación. Por una parte, eran los encargados de recibir juramentos de las facciones en garantía del cese de las hostilidades. Por otro lado, sobre ellos recaía el peso litúrgico y ceremonial de los actos religiosos en pro de la (teórica) paz o tregua alcanzada. Y por último, los clérigos neutrales tenían la labor de resolver los problemas que hubiese con las personas eclesiásticas afectadas por los conflictos, con aquellos de sus miembros que más implicados habían estado en las épocas de tensión, y que en consecuencia se habían visto más perjudicados por ellas. En este terreno hay que destacar a los llamados o desterrados, esto es, los que con motivo de los incidentes tuvieron que huir o fueron expulsados de la ciudad por la parcialidad vencedora, y cuyo regreso había que preparar pasado un tiempo como signo de paz y buena voluntad. No era una cuestión baladí, ya que las fórmulas empleadas no siempre eran del agrado de todos, máxime cuando había dinero de por medio - en concreto, el de las distribuciones cotidianas que los capitulares percibían por asistir a los oficios litúrgicos - Los expulsados reclamaban poder participar de esas cantidades, ya que no era por su voluntad que no podían volver a la urbe, y el cabildo en diversos ordenamientos otorgados entre 1470 y 1471 así lo dispuso como prueba de su buena voluntad, excluyendo sólo a quienes el propio cabildo hubiera echado por deméritos ${ }^{72}$. Pese a esa buena disposición, el regreso de los beneficiados no siempre era fácil, y solía poner a prueba la capacidad negociadora del cabildo con los representantes del rey o de la ciudad sobre las condiciones y el momento en que debía producirse. De ahí que los ordenamientos tratando de ajustar mejor la cuestión se prolongaran incluso hasta comienzos del siglo XVI ${ }^{73}$.

La implicación más directa del cabildo en la consecución de la paz urbana se veía reflejada, además, en los territorios de alrededor de la urbe bajo su

71 FERNÁNDEZ COLLADO y LOP OTÍN, 2010.

72 ACT, Actas Cap. I, f. 28r y 36r-v.

73 LOP OTÍN, 2003: 328-329. 
señorío. Tal vez el ejemplo más paradigmático sea el de la villa de Ajofrín, situada en la comarca de la Sisla, a la que vimos acudir en auxilio del templo cuando en julio de 1467 sufrió el asedio mencionado. Según el canónigo Gómez de Mesa, ciento cincuenta hombres bien armados, principales y plebeyos, se desplazaron hasta Toledo para liberar el templo, sufriendo diversas heridas y menoscabos en sus personas. Es posible que en agradecimiento por esta colaboración unos años después el cabildo dictase unas ordenanzas, fechadas entre 1469 y 1479, en las que se ocupó de velar por el bien e pro de la republica de la dicha villa e de los vecinos e moradores della ${ }^{74}$. Junto a cuestiones de índole económica, se establecieron una serie de medidas complideras al serviçio de Dios y desta Sancta Yglesia, y al bien e utylidad e paçificaçion de la villa, adoptadas el 7 de enero de 1476. El cabildo diputó para ello a uno de sus miembros más destacados, el canónigo y nuncio, Francisco Ortiz, con poderes para suspender oficios, poner treguas, dictar destierros y, en suma, disponer los castigos y multas que fueran oportunos ${ }^{75}$.

Las ordenanzas dadas por el nuncio tras reunirse en la iglesia de Santa María Magdalena de la villa con sus autoridades y algunos vecinos se sustanciaron en tres pregones. En el primero se prohibió llevar armas ofensivas y defensivas. En el segundo se instaba a los vecinos y moradores a acudir a la llamada de los alcaldes y el alguacil de la villa cuando fueren requeridos para colaborar con la justicia. En el tercero, por último, se aludía a las divisiones, cuestiones y ruydos existentes en la villa - tal vez a causa de las propias divisiones que existían en Toledo-, aunque no precisaban los motivos. De hecho, esta era la razón que obligó al representante capitular a personarse en Ajofrín: la necesidad de los poner en paz e en treguas, para lo cual ordenó que cada vez que hubiera una riña de palabra como de fecho nadie entre los vecinos ayudara ni favoreciera a una de las partes, salvo para ponerlos en $p z^{76}$. En todo caso, la medida no fructificó, por lo que dos años después - en 1478 - un nuevo pregón renovó el compromiso del cabildo con el bien e pas e sosiego de la villa, en la que por entonces, según los documentos, habitaban personas escandalosas que promovían ruydos entre los vecinos y no pechaban en contia ninguna por ser pobres ${ }^{77}$. La documentación no precisa más, pero sí deja significativa constancia de la preocupación del cabildo por lograr la paz o, cuanto menos, escenificarla, además de en Toledo, en los lugares de su jurisdicción.

74 ACT, A.1. B.4.6, f. 3v.

75 Ibidem, ff. 8r-8v.

76 Ibidem, ff. 9r-10r.

77 Ibidem, ff. 13v-14v. En esta ocasión el cabildo está representado por los canónigos Diego de Villaminaya, Luis Daza y García Fernández de Alcalá. 


\section{A MOdo de CONCLUSIÓN}

A pesar de la ingente bibliografía que existe sobre los movimientos sociales y las actividades subversivas de las élites urbanas, aún queda mucho por conocer sobre los procesos por los cuales toda una población podía ser escandalizada o sometida a una paz concreta, en unas circunstancias muy específicas. Por una parte, la historiografía, más que plantear a los documentos conservados nuevas preguntas, lo que ha hecho, a menudo, ha sido intentar responder de manera distinta a las cuestiones de siempre. Y por otra, a veces se han dado por obvios aspectos que no lo son, marginándose su análisis, como por ejemplo todo lo relativo a las ceremonias pacificadoras de las poblaciones sublevadas ${ }^{78}$. Lo que está claro es que la sociedad bajomedieval - muy distinta de la actual sociedad de la información - daba mucha importancia al simbolismo y a las ceremonias rituales a la hora de establecer los consensos o explicitar los conflictos, y que la coreografía ritual se halla en múltiples aspectos de la vida del pasado, esclareciendo cuestiones de nuestro presente que pueden parecer contemporáneas - como, por ejemplo, el hecho de manifestarse en masa a la hora de exigir algo- . Hay cuestiones, en todo caso, que aun percibiéndose y pudiéndose leer entrelíneas en los textos conservados, apenas han dejado huella documental en lo relativo a Toledo, en particular, y a la Corona de Castilla, más globalmente. Por ejemplo, es muy posible que existiesen cánticos de las facciones; que los miembros de una determinada facción se identificaran entre sí a través, no sólo de gritos estereotipados y apellidos — ¡Silvas! ¡Ayalas! ¡Santiago! ¡Sancta María! ¡Comunidad! ¡Libertad! - , sino con cancioncillas de origen popular que circulaban entre la población, y que eran empleadas en el momento de unirse en la lucha contra el rival, lo mismo que existían cancioncillas reivindicativas que circulaban entre el común de las ciudades. Sí se han conservado, por el contrario, los motes que unas facciones ponían a otras, dado que la estigmatización, la segregación peyorativa y los perjuicios frente al otro eran fundamentales para definir al grupo propio ${ }^{79}$. En Toledo los Ayala llamaban a los judeoconversos, y por extensión a los Silva, marranos; y éstos a sus opositores, lindos.

No hay datos sobre otras cuestiones que podrían ser aclaratorias sobre los procesos rituales que se seguían en la pacificación y el alzamiento. Los textos indican que las facciones se articulaban en torno a una determinada simbología de pendones, banderolas y escudos pertenecientes a los linajes de los líderes de la parcialidad (símbolos visibles incluso en las fachadas de sus palacios), y que cada una tenía sus propias parroquias y su territorio específico en la urbe, pero se desconoce si sus miembros se identificaban y definían su per-

78 BENHAM, 2011: 1-2.

79 OFFENSTADT, 2007: 137-138. 
sonalidad como grupo mediante un determinado tipo de vestimenta, de arma o de saludo.

Resulta evidente, en todo caso, y como conclusión final, que tanto a la hora de sublevarse como de hacer la paz existía un vínculo muy poderoso entre las acciones rituales - $\mathrm{O}$ ritualizadas - establecidas por la costumbre y las prácticas judiciales, religiosas y políticas, de las que se apropiaban las facciones en beneficio propio. Si en el momento de alzar a la facción todos sus integrantes gritaban al unísono (la voz de la parcialidad) era porque también se debía hacer así en las iglesias, cuando se reunían los parroquianos para elegir a uno de sus jurados, cuando se vociferaba, ;Aqui vedes a nuestro jurado! (la voz de la parroquia) ${ }^{80}$. Si en la gesticulación de la paz era muy importante darse la mano, se debía a que rememoraba el saludo de la paz entre cristianos que se debía producir en la misa. Por último, si durante el caos y la violencia provocados por las facciones hubo espectáculos del terror, en los que se ajusticiaba a los enemigos paseándolos en un burro por las calles, con una turbamulta de hombres armados detrás y un pregonero anunciando sus supuestos delitos, era porque así lo hacía la justicia. Lo importante, en todos los casos, era la publicidad, que toda la urbe conociera que un determinado sector de la élite acudía a las armas, o que, por el contrario, se erigía en adalid de una paz que era la mejor para todos, supuestamente. Tanto en la paz como en la violencia, el papel del rito y la presencia de las muchedumbres - de las clientelas armadas - eran una obligación, puesto que servían para robustecer las posturas asumidas, para darles legitimidad e incluso para conferirles una sanción cuasi-sagrada.

\section{BIBLIOGRAFÍA}

Beltrán, Miquel, «Maimónides sobre las creencias necesarias en el orden político», en Pedro Roche Arenas (coord.), El pensamiento político en la Edad Media, Madrid, Ramón Areces, 2010: 17-39.

Benham, Jenny, Peacemaking in the Middle Ages. Principles and Practice, Manchester and New York, Manchester University Press, 2011.

Blockmans, Win, «La répression de révoltes urbaines comme méthode de centralization dans les Pays-Bas bourguignons», Publications du Centre européen d'études bourguignonnes (XIV - $X V^{e}$ siècles), 28 (1988): 5-9.

Blockmans, Win, «La manipulation du consensus. Systèmes de pouvoir à la fin du Moyen Âge», en Sergio Gensini (edit.), Principi e citta alla fine del Medioevo, Pisa, Pacini, 1996: 433-447.

80 LÓPEZ GÓMEZ, 2012a: 738.

Hispania, 2015, vol. LXXV, nº. 249, mayo-agosto, págs. 413-440, ISSN: 0018-2141, e-ISSN: 1988-8368, doi: 10.3989/hispania.2015.013 
Cohn, Samuel K. (Jr.), Lust for Liberty. The Politics of Social Revolt in Medieval Europe. 1200-1425. Italy, France and Flanders, Cambridge, Massachusetts and London, Harvard University Press, 2008.

Criado Vega, Teresa, «Los actos de la paz. Técnicas de perfumería y cosmética en recetarios castellanos de los siglos XV y XVI», Anuario de Estudios Medievales, 41/2 (2011): 865-897.

Dacosta, Arsenio, «Violencia banderiza y memoria histórica: un estudio comparado», en Jon Andoni Fernández de Larrea y José Ramón Díaz de Durana (edits.), Memoria e historia. Utilización política en la Corona de Castilla al final de la Edad Media, Madrid, Sílex, 2010: 101-139.

Dumolyn, Jan y Haemers, Jelle, «A Bad Chicken Was Broading»: Subversive Speech in Late Medieval Flanders, Past and Present. A Journal of Historical Studies, 214 (February 2012): 45-86.

Fernández Collado, Ángel y Lop Otín, María José, «Las procesiones de Toledo en la Edad Moderna: punto de encuentro entre la catedral y las instituciones religiosas de la ciudad», Memoria Ecclesiae, XXXIV (2010): 321-349.

Fletcher, Christopher, «Manhood, Kingship and the Public in Late Medieval England», Edad Media. Revista de Historia, 13 (2002): 123-142.

Foronda, François, y Carrasco Manchado, Ana Isabel (dirs.), El contrato político en la Corona de Castilla. Cultura y sociedad políticas entre los siglos X al XVI, Madrid, Dykinson, 2008.

García Vera, María José y Castrillo Llamas, María Concepción, «Nobleza y poder militar en Castilla a fines de la Edad Media», Medievalismo, 3 (1993): 19-37.

Izquierdo Benito, Ricardo, «La noche de Toledo en el siglo XV», Toletum, 30 (1994): 123-142.

Izquierdo Benito, Ricardo, «Causas de la violencia contra los conversos de Toledo en el siglo $X V »$, en Rica Amran Cohen (coord.), Violence et identité religieuse dans l'Espagne du XVe au XVIIe siècles, París, Université de Picardie Jules Verne, 2011:163-180.

Jara Fuente, José Antonio, «Legitimando la dominación en la Cuenca del siglo XV: la transformación de los intereses particulares a través de la definición del bien común», Anales de la Universidad de Alicante. Historia medieval, 16 (20092010): 93-109.

Kershaw, Paul J. E., Peaceful Kings. Peace, Power and the Early Medieval Political Imagination, Oxford-New York, Oxford University Press, 2011.

Lacey, Helen, «Protection and Immunity in Later Medieval England», en Tom B. lambert y David Rollason (edits.), Peace and Protection in the Middle Ages, Centre of Medieval and Renaissance Studies-Durham University, Toronto, Pontificial Institute of Medieval Studies, 2009: 78-96.

Lavelle, Ryan, «Toward a Political Contextualization of Peacemaking and Peace Agreements in Anglo-Saxon England», en Diane Wolfthal (edit.), Peace and Ne- 
gotiation: Strategies for Coexistence in the Middle Ages and the Renaissance, Brepols, Arizona Studies in the Middle Ages and the Renaissance, 2000, 4: 39-55.

Lop Otín, María José, «La inmunidad judicial del clero catedralicio toledano en la Edad Media (siglos XI-XV), en La Administración de Justicia en la Historia de España, Guadalajara, Anabad-Castilla-La Mancha, 1999, I: 545-560

Lop Otín, María José, El cabildo catedralicio de Toledo en el siglo XV. Aspectos institucionales y sociológicos, Madrid, Fundación Ramón Areces, 2003.

Lop Otín, María José, «Un grupo de poder a fines de la Edad Media: los canónigos de la catedral de Toledo», Anuario de Estudios Medievales, 35/2 (2005): 635-669.

López Gómez, Óscar, «Claves del sistema de pacificación ciudadana desarrollado por los Reyes Católicos en Toledo (1475-1485)», En la España medieval, 27 (2004): 165-193.

López Gómez, Óscar, «Pas e sosyego. Un argumento de acción política en la Castilla Bajomedieval», Medievalismo, 16 (2006a): 41-71.

López Gómez, Óscar, Violencia urbana y paz regia: el fin de la época medieval en Toledo (1465-1522). Tesis doctoral leída en la Facultad de Humanidades de Toledo, 2006b. En RUIdeRA [Repositorio Universitario Institucional de Recursos Abiertos. Universidad de Castilla-La Mancha]. Página web: http://hdl.handle.net/10578/2771.

López Gómez, Óscar, La sociedad amenazada. Crimen, delincuencia y poder en Toledo a finales del siglo XV, Toledo, Ayuntamiento de Toledo, 2006c.

López Gómez, Óscar, Los Reyes Católicos y la pacificación de Toledo, Madrid, Castellum, 2008a.

López Gómez, Óscar, «Acogerse a sagrado: violencia, poder y recintos eclesiásticos a fines del Medievo», en Juan Carlos Vizuete Mendoza y Julio Martín Sánchez (coords.), Sacra loca toletana. Los espacios sagrados en Toledo, Cuenca, Universidad de Castilla-La Mancha, Cuenca, 2008b: 189-222.

López Gómez, Óscar, «Representatividad política y rebelión social a finales del Medievo: las asambleas del común en Toledo (1478-1522)», Anuario de Estudios Medievales, 42/2 (2012a):727-753.

López Gómez, Óscar, «Después de Isabel la Católica: la reaparición de la lucha de facciones en Toledo», Anales de la Universidad de Alicante. Historia Medieval, 18 (2012b): 315-343.

López Gómez, Óscar, La paz en el Medievo: líneas de análisis y entorno historiográfico, Madrid, Sociedad Española de Estudios Medievales, 2013.

López Gómez, Óscar, «El impacto de las revueltas urbanas en el siglo XV. A propósito de la rebelión de 1449 en Toledo», Edad Media. Revista de Historia, 15 (2014): 175-191.

Mackay, Angus, «La semiología y los ritos de violencia: sociedad y poder en la Corona de Castilla», En la España medieval, 11 (1988): 153-165.

Mackay, Angus, «La conflictividad social urbana», en Las ciudades andaluzas (siglos XII-XVI). Actas del VI Coloquio internacional de Historia Medieval andaluza, Málaga, Universidad de Málaga, 1991a: 509-524. 
Mackay, Angus, «Los bandos: aspectos culturales», en Bandos y querellas dinásticas en España al final de la Edad Media. Actas del coloquio celebrado en la Biblioteca Española de París los días 15 y 16 de mayo de 1897, Madrid, Ministerio de Asuntos Exteriores, 1991b: 15-28

Martín Gamero, Antonio, Historia de la ciudad de Toledo, sus claros varones, sus monumentos, Toledo, Zocodover, 1979 (Ed. facsímil de la de 1862).

Martines, Lauro, «The Authority of Violence: Notes on Renaissance Florence», en Elodie Lecuppre-Desjardin y Anne-Laure Van Bruaene (edits.), Emotions in the Heart of the City $\left(14^{\text {th }}-16^{\text {th }}\right.$ Century): Studies in European Urban History, 5 (1100-1800), Brepols, Turnhout (Belgium), 2005: 31-39.

Martínez Gil, Fernando, «Furia popular. La participación de las multitudes urbanas en las Comunidades de Castilla», en MARTÍNEZ GIL, F. (Coord.), En torno a las Comunidades de Castilla. Actas del Congreso Internacional «Poder, conflicto y revuelta en la España de Carlos I», Cuenca, Universidad de Castilla-La Mancha, 2002: 309-364.

Monsalvo Antón, José María, «Ideario sociopolítico y valores estamentales de los pecheros abulenses y salmantinos (ss. XIII-XV)», Hispania, LXXI/238 (2011): 325-362.

Mullet, Michael, La cultura popular en la Baja Edad Media, Barcelona, Crítica, 1990.

Muñoz Gómez, Victor, «Bandos urbanos y pacificación señorial en la Castilla bajomedieval: Paredes de Nava y Fernando de Antequera (1400-1416)», Anuario de Estudios Medievales, 39/2 (2009): 667-701.

Netanyahu, Benzion, Los orígenes de la Inquisición en la España del siglo XV, Barcelona, Crítica, 1999.

Nieto Soria, José Manuel, «Más que palabras. Los instrumentos de la lucha política en la Castilla bajomedieval», en José Ignacio de la Iglesia Duarte (coord.), Conflictos sociales, políticos e intelectuales en la España de los siglos XIV y XV, Logroño, Gobierno de La Rioja, 2004: 165-204

Nikichine, Mario, La justice et la paix à Douai à la fin du Moyen Âge: la pratique de la grâce. Bibliographie commentée, París, École nationale supérieure des sciences de l'information et des bibliothéque, París, 2006.

Nogales Rincón, David, «La cultura del pacto en las relaciones diplomáticas lusocastellanas durante el período trastámara (1369-1504)», En la España medieval, 35 (2012): 121-144.

Offenstadt, Nicolas, «Interaction et régulation des conflicts. Les gestes de l'arbitrage et de la conciliation au Moyen Âge (XIII'-XV' ${ }^{\mathrm{e}}$ siècles)», en Claude Gauvard y Robert Jacob (dirs.), Les rites de la justice. Gestes et rituels judiciaires au Moyen Âge, París, Le leopard d'or, 2000: 201-222.

Offenstadt, Nicolas, «Paix de Dieu et paix des hommes. L'action politique à la fin du Moyen Âge», Politix, 15/58 (2002): 61-81. 
Offenstadt, Nicolas, Faire la paix au Moyen Âge. Discours et gestes de paix pendant la Guerre de Cent Ans, París, Odile Jacob, 2007.

Passini, Jean, Casas y casas principales urbanas. El espacio doméstico de Toledo a fines de la Edad Media, Toledo, Universidad de Castilla-La Mancha, 2004.

Petkov, Kiril, The Kiss of Peace: Ritual, Self and Society in the High and Late Medieval West, Leiden-Boston, Brill Academic Publishers, 2003.

Pulgar, Fernando de, «Crónica de los Señores Reyes Católicos don Fernando y doña Isabel de Castilla y Aragón», en Crónicas de los Reyes de Castilla, Madrid, BAE, 1953, vol. LXX.

Rollason, David, «Protection and the Mead-Hall», en Tom B. Lambert y David Rollason (edits.), Peace and Protection in the Middle Ages. Centre for Medieval and Renaissance Studies-Durham University, Pontificial Institute of Medieval Studies, Toronto, 2009: 19-35.

Sanmartín, Israel, «La construcción de las historias de la paz a partir de la Edad Media y de la historia inmediata», Cuadernos de estudios gallegos, LVII/123 (2010): 413-431.

Vaquero Serrano, María del Carmen, López Muñoz, Tomás, Picón García, María Luisa y Ortiz Díez, María, El proceso contra Juan Gaitán, Toledo, Imprenta Serrano, 2000.

Wilcox, Jonathan, «The St. Brice's Day Massacre and Archbishop Wulftand», en Wolfthal, Diane (edit.), Peace and Negotiation: Strategies for Coexistence in the Middle Ages and the Renaissance, Brepols, Arizona Studies in the Middle Ages and the Renaissance, 2000, 4: 79-91.

Wolfthal, Diane (edit.), Peace and Negotiation: Strategies for Coexistence in the Middle Ages and the Renaissance, Brepols, Arizona Studies in the Middle Ages and the Renaissance, 2000, 4.

Yezdi Malegam, Jehangir, The Sleep of Behemoth. Disputing Peace and Violence in Medieval Europe, 1000-1200, Ithaca (New York), Cornell University Press, 2013.

Recibido: 21/10/2013

Aceptado: 08/09/2014 